\title{
Reply to comment to: A systematic review of the surgical treatment of large incisional hernia. T. Georgiev-Hristov, A. Celdrán. Hernia 2015; 19:89-101
}

\author{
E. B. Deerenberg ${ }^{1}$
}

Received: 19 July 2015/Accepted: 3 August 2015/Published online: 22 August 2015

(C) Springer-Verlag France 2015

We thank Tihomir Georgiev-Hristov and Ángel Celdrán for their comment on our review on the surgical treatment of large incisional hernias. The authors suggest a double-mesh technique for the closure of large incisional hernias. The results of our review are in line with their statement that the use of a mesh reduces the recurrence rate. The use of two meshes in different planes of the abdominal wall is an interesting concept. However, as they describe in their comment, all articles on 'double mesh' techniques advocate a different surgical repair. Meshes are placed in different planes of the abdominal wall, some techniques are bridging, others insist on midline closure, even applying additional releases or component separation techniques.
The varying techniques make it different to compare outcomes and complication rates. We would like to encourage a high-quality cohort study with a clearly described doublemesh technique to make the results of this technique comparable to the techniques reported in our review.

Kind regards,

On behalf of all authors,

Eva B. Deerenberg

\section{Compliance with ethical standards}

Conflict of interest Deerenberg EB declares that she has no conflict of interest.
This reply refers to the article available at doi:10.1007/s10029-015-1393-2.

E. B. Deerenberg

e.deerenberg@erasmusmc.nl

1 Department of Surgery, ErasmusMC, Rotterdam, The Netherlands 